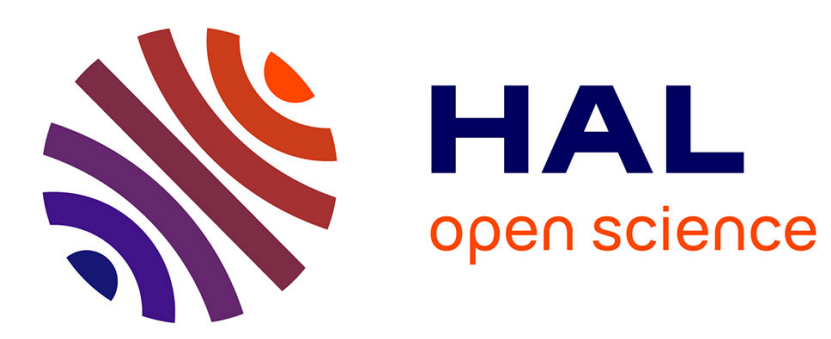

\title{
Control of a Segregation during Directional Solidification of the Manganese-Zinc Ferrite
}

W. Wolczynski, E. Guzik, R. Ciach, J. Kloch

\section{To cite this version:}

W. Wolczynski, E. Guzik, R. Ciach, J. Kloch. Control of a Segregation during Directional Solidification of the Manganese-Zinc Ferrite. Journal de Physique IV Proceedings, 1997, 07 (C1), pp.C1-77-C1-78. 10.1051/jp4:1997119 . jpa-00254839

\section{HAL Id: jpa-00254839 https://hal.science/jpa-00254839}

Submitted on 1 Jan 1997

HAL is a multi-disciplinary open access archive for the deposit and dissemination of scientific research documents, whether they are published or not. The documents may come from teaching and research institutions in France or abroad, or from public or private research centers.
L'archive ouverte pluridisciplinaire $\mathbf{H A L}$, est destinée au dépôt et à la diffusion de documents scientifiques de niveau recherche, publiés ou non, émanant des établissements d'enseignement et de recherche français ou étrangers, des laboratoires publics ou privés. 


\title{
Control of a Segregation during Directional Solidification of the Manganese-Zinc Ferrite
}

\author{
W. Wolczynski, E. Guzik*, R. Ciach and J. Kloch** \\ Institute of Metallurgy and Materials Science, Polish Academy of Sciences, 30059 Krakow, Reymonta 25, \\ Poland \\ * Faculty of Foundry, University of Mining and Metallurgy, 30059 Krakow, Reymonta 23, Poland \\ ** Institute of Mathematics, Polish Academy of Sciences, 31027 Krakow, Sw. Tomasza 30, Poland
}

\begin{abstract}
The composition of the $\mathrm{ZnFe}_{2} \mathrm{O}_{4}-\mathrm{MnFe}_{2} \mathrm{O}_{4}$ ferrite has been determined on the basis of pseudobinary phase diagram calculated on the assumption that chemical potential of both components are equal for both liquid and solid solutions. A single crystal has been produced applying method of the directional solidification. The open Bridgman system with oxygen atmosphere of a proper pressure, a positive temperature gradient, constant growth rate and continuous addition of an alloy of the nominal concentration has been applied. The chemical segregation along the longitudinal axis of obtained single crystal has been examined by means of scanning electron microscopy. The possibly small distances between analysed areas has been applied. Some obtained results of measurements have been compared with those of calculations. The improvedBrody - Flemings' theory worked out for linear and parabolic movement of the local $s /$ interface has been used for the calculations. The obtained micrographs have allowed to control considered segregation via theoretical prediction and decrease an inhomogeneity. For that reason three features of both theoretical and experimental curves have been differentiated and analysed.
\end{abstract}

\section{INTRODUCTION}

The cores for video heads are preferably made of manganese-zinc ferrite manufactured as a single crystal. Their properties satisfy the advanced requirements connected to high resistivity, small eddy-current losses, high values of saturation induction of the initial and maximum magnetic permeability and of Curie point. Both shots with high degree of accuracy and smoothness of the head front are possible to be obtained due to single crystal properties, contrary to properties of common sintered ferrites as shown by Lagrange et al. [1], Sadatoshi [2] and Watanabe and Yamaga [3]. Directional solidification in Bridgman system is the most commonly accepted method for the production of single crystal of manganese-zinc ferrites. The process under investigation is carried out in an open system where the liquid is continuously enriched with components subjected to segregation, [4], [5] in order to ensure a required homogeneity in the product.

In the case of closed Bridgman system whole batch of an alloy is melted in the crucible and next subjected to directional solidification. The method was applied by Sugimoto [6] and Wang and Zhang [7] and significant segregation of components along the vertical axis of crystal was revealed.

The inhomogeneity is however an undiserable effect, since it reduces the utility properties of the crystal. The sufficient homogeneity of crystal may be obtained when the solidification process is carried out under control that is in an open system.

\section{METHOD}

The control is performed in two ways: by small modifications of temperature profile shown in Figure 1 and reproductions of nominal concentration in the liquid, $\left(N_{0}\right)$. The well-chosen temperature field ensures existence of several degrees temperature zone within which the liquid drops come into being. The existence of temperature zone associated with adequate growth rate ensure the reproduction of nominal concentration of the liquid. Eventually, reproduction of nominal concentration and back diffusion in the solid protect against too high segregation in the single crystal. The measurement of concentration performed along vertical axis of the single crystal using EDS technique compared with the results of segregation prediction allow to choose adequate temperature zone and appropriate growth rate for solidification.

A distance between measurement points was chosen as small as possible and was equal to $250 \mu$ m. The concentration of three elements $\mathrm{Fe}, \mathrm{Mn}$ and $\mathrm{Zn}$ has been measured. The equations for segregation are given as follows, [8]:

$d((1-x) \cdot N)+k \cdot N \cdot d x+A \cdot k \cdot d N=0 \quad A=(D / L) \cdot(d t / d l)$

$x(N)=\left[Q(N)-Q\left(N_{0}\right)\right] \exp (-P(N)) \quad Q(N)=(1+A) \int\left(f_{A} / N\right) \exp P(N) d N-A \int(1 / N) \exp P(N) d N \quad P(N)=\int\left(f_{A} / N\right) d N$ 
$x$

$k$

$l$

$f_{A}=k(M)$ approximation function, amount of single crystal at a given stage of crystal growth, $\mathrm{N}$ distribution coefficient, position of the local s/l interface, current concentration of solute in the liquid, diffusion coefficient of solute in the solid, one half dendrite arm spacing, time.

\section{RESULTS}

The results of theoretical prediction have been obtained using the approximation function $f_{A}$, calculated on the basis of mentioned phase diagram, then introduced into equations (1), (2). The method of continuous addition of an alloy of the nominal concentration has been taken into account, (Figure 1). The results of calculations and measurements are shown in Figure 2.

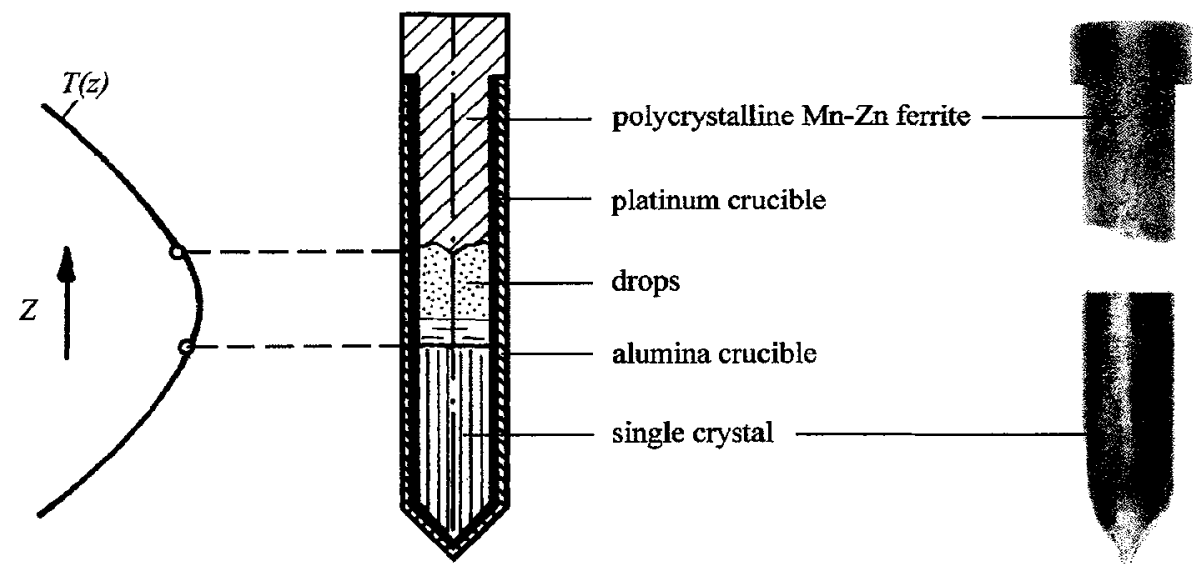

Figure 1: Temperature profile applied in Bridgman system used for investigation and a manganese - zinc ferrite before/after solidification
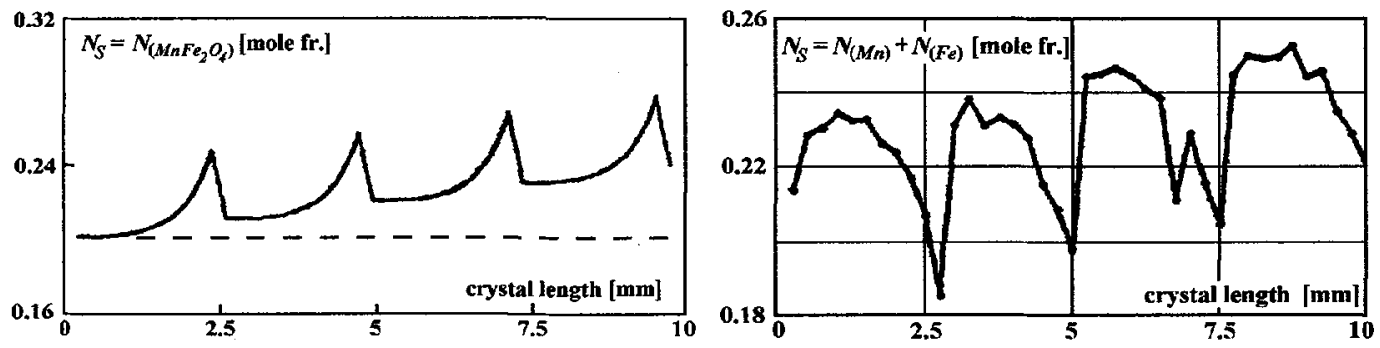

Figure 2: Theoretical curve of segregation and concentration of the $(\mathrm{Mn}+\mathrm{Fe})$ - elements along an axis of ferrite single crystal for four drops

Both theoretical and experimental curves have three characteristic features: 1) periodicity associated with frequency of proportioning of drops, 2) monotonicity of average concentration connected with solute segregation, 3) curvature associated with the nature of segregation in each period due to variation of distribution coefficient along the liquidus line, $k(N)$.

According to idea of process control and the results of simulations, (Figure 2a), as well as measurements, (Figure 2b): 1) periodicities of both curves are coincident, 2) monotonicity of both average concentration of the $\mathrm{MnFe}_{2} \mathrm{O}_{4}-$ component and average concentration of the $(\mathrm{Mn}+\mathrm{Fe})$ - elements are similar, 3) curvature of both profiles are different, and the last prove that applied theory has some imperfections and is to be modified.

\section{References}

[1] Lagrange A., Nicolas J. and Hildebrandt M., Trans.Magn.IEEE, 8 (1972) 494-498.

[2] Sadatoshi J., Radio Mentor., 6 (1972) 237-241.

[3] Watanabe H. and Yamaga I., Trans.Magn.IEEE, 8 (1972) 497-501.

[4] Berben T.J. , Perduijn D.J. and Damen J.P.M., Ferrites, (Proceedings of the International Conference 1980) pp. $722-725$.

[5] Fischer R.D. and Blades I.D., Trans.Magn.IEEE, 8 (1972) 232-235.

[6] Sugimoto M., J.Appl.Phys., 5 (1966) 557-564.

[7] Wang G. and Zhang R., Trans.Magn.IEEE, 16 (1980) 882-883.

[8] Wolczyński W. and Morawiec A., Metallurgy and Foundry, 16 (1990) 365-384. 